\title{
High SLC20A1 Expression Is Associated With Poor Prognoses in Claudin-low and Basal-like Breast Cancers
}

\author{
CHOTARO ONAGA ${ }^{1}$, SHOMA TAMORI ${ }^{1}$, HITOMI MOTOMURA ${ }^{1}$, AYAKA OZAKI ${ }^{1}$, \\ CHIKA MATSUDA ${ }^{1}$, IZUMI MATSUOKA ${ }^{1}$, TAKUMA FUJITA ${ }^{1}$, YUKA NOZAKI ${ }^{1 *}$, \\ YASUSHI HARA ${ }^{2}$, YOHEI KAWANO ${ }^{3}$, YOHSUKE HARADA ${ }^{1}$, TSUGUMICHI SATO ${ }^{3}$, \\ YASUNARI MANO ${ }^{3}$, KEIKO SATO ${ }^{4}$ and KAZUNORI AKIMOTO ${ }^{1}$ \\ ${ }^{1}$ Department of Medicinal and Life Sciences, Faculty of Pharmaceutical Sciences, \\ Tokyo University of Science, Chiba, Japan; \\ ${ }^{2}$ Research Institute for Biomedical Sciences, Tokyo University of Science, Chiba, Japan; \\ ${ }^{3}$ Department of Pharmacy, Faculty of Pharmaceutical Sciences, Tokyo University of Science, Chiba, Japan; \\ ${ }^{4}$ Department of Information Sciences, Faculty of Science and Technology, \\ Tokyo University of Science, Chiba, Japan
}

\begin{abstract}
Background/Aim: SLC20Al has been identified as a prognostic marker in ER+ breast cancer. However, the role of SLC20A1 expression in breast cancer subtypes other than the ER+ types remains unclear. Materials and Methods: Genomics datasets were downloaded and analyzed, and the effect of SLC20A1 knockdown using targeted siRNA on cell viability and tumor-sphere formation was assessed. Results: SLC20A1 high patients with ER+, claudin-low or basal-like breast cancers showed poor prognoses. SLC20A1 ${ }^{\text {high }}$ patients treated with radiotherapy had poor clinical outcomes. SLC20A1 knockdown suppressed the viability of MDA-MB 231 (claudin-low), MDA-MB 468 (basal-like) and MCF-7 (ER+) cells, and tumor-sphere formation by ALDH1 ${ }^{\text {high }}$ cells. These results suggest that SLC20A1 is involved in cancer progression and contributes to clinical outcomes in patients with ER+, claudin-low and basal-like breast cancers. Conclusion: SLC2OAl is a potential prognostic marker and therapeutic target in ER+, claudin-low and basal-like breast cancers.
\end{abstract}

Breast cancer is the most commonly occurring cancer among women worldwide, with 2.1 million new cases $(24.2 \%$ of all

This article is freely accessible online.

*Current affiliation: Exploratory Oncology Research \& Clinical Trial Center, National Cancer Center, Chiba, Japan

Correspondence to: Kazunori Akimoto, Ph.D., 2641 Yamazaki, Noda, Chiba 278-8510, Japan. Tel: +81 471213614, Fax: +81 471213614,e-mail: akimoto@rs.tus.ac.jp

Key Words: Breast cancer, SLC20A1, prognostic marker, cancer stem cell, ALDH1, claudin-low, basal-like. cancers in women) and 0.6 million cancer-related deaths (15.0\% of all cancer-related deaths among woman) annually (1). Breast cancer is classified using immunohistochemistry (IHC) and gene expression patterns (PAM50) (2-7). Based on IHC, breast cancer is classified into four types: ER+ and/or PgR+ HER2 - type, ER+ and/or PgR+ HER2+ type, ER - and PgR- HER2+ type and triple negative type (TNBC). Based on PAM50, breast cancer is classified into at least six subtypes: normal-like, luminal A, luminal B, HER2-enriched, claudin-low and basal-like (2-7). Among these, the luminal A and luminal B types express ER $(8,9)$, and some luminal B and HER2-enriched types express HER2 (4, 8-11). Many claudin-low and basal-like types overlap with the TNBC type $(6,12-14)$.

Breast cancer treatment mainly entails surgery, radiotherapy and drug therapy, which may include chemotherapy, endocrine therapy and/or molecular target therapy. Overall, breast cancer prognosis is good. Endocrine therapy is selected against ER+ type and a HER2-targeted antibody, such as trastuzumab, is used to treat HER2 type $(11,15,16)$. However, there is no effective drug or molecular targeted therapy for TNBC or its overlapping claudin-low and basal-like types. Consequently, those patients are treated only with surgery, radiotherapy and chemotherapy, and have poor prognoses $(6,13,15-17)$. Moreover, it is also known that in some of these cases, chemo- and/or radiotherapy actually stimulates cancer progression (18-20). It is therefore essential to identify effective prognostic markers and molecular targets that can be exploited for the treatment of the claudin-low and basallike breast cancer subtypes.

A major hurdle that must be overcome for therapy to be effective against the claudin-low and basal-like subtypes is 
their high degree of stemness $(12,21)$. Tumors consist of both differentiated cancer cells and cancer stem cells (CSCs). CSCs are largely undifferentiated tumorigenic cells that exhibit stem-like functions such as self-renewal and multipotency $(22,23)$. Because most CSCs are resistant to conventional chemo- and radio-therapies, development of targeted therapies against CSCs is very much needed to improve the clinical outcomes of patients with these cancers $(21,22,24)$. ALDH1 is an enzyme that converts aldehydes to carboxylic acids and is abundant in TNBC (25-27). Among the ALDH1 genes, ALDH1Al and ALDH1A3 are known to be CSC markers in several cancers $(25,28-33)$. In particular, $A L D H 1 A 1$ is enriched in claudin-low type breast cancers while $A L D H 1 A 3$ is enriched in the basal-like type (34).

SLC20A1/PiT1 encodes the sodium/inorganic phosphate (Pi) symporter, which was originally identified as a mammalian retroviral receptor (35) and is responsible for the uptake of Pi into cells (36). SLC20A1 is expressed in various tissues and plays a fundamental housekeeping role supplying Pi to cells $(35,36)$. SLC20A1 gene knockout mice exhibit hypoplastic livers accompanied by a cell proliferative defect and induced cell death that result in embryonic lethality at E12.5 (37). SLC20A1 promotes cell proliferation in murine pre-osteoblastic cells, NIH3T3 cells, primary mouse embryonic fibroblasts, human HepG2 cells and HeLa cells (37-39), and it is also involved in tumor formation by HeLa cells in xenografted mice (39). SLC20A1 is highly expressed in human somatotroph adenomas and is involved in the proliferation and migration of $\mathrm{GH} 3$ cells derived from somatotroph adenomas (40). We recently reported that high SLC20A1 expression correlates with poor prognosis of ER+ breast cancer (41). However, the role of SLC2OAl expression in breast cancer subtypes other than the ER+ type remains unknown, as does its function in ALDH1+ breast CSCs. In this report, we show that $S L C 20 A 1$ expression is a potential prognostic marker for ER+, claudin-low and basal-like breast cancers and that SLC20A1 depletion suppressed the viability of ER+, claudin-low and basal-like breast cancer cells as well as in vitro tumor-sphere formation by ALDH1 ${ }^{\text {high }}$ cells .

\section{Materials and Methods}

Analysis of The Cancer Genome Atlas dataset. The Cancer Genome Atlas (TCGA) breast cancer dataset (42) was downloaded from Oncomine (43) on January 9, 2020. The clinicopathological data from these patients have been summarized previously (34). This dataset contains mRNA expression data from 61 normal breast tissue samples and 532 primary breast tumor samples. Expression of SLC20A1 mRNA (reporter: A_23_P165656) was compared between the normal and cancer tissues, and the $p$-value was calculated using the Mann-Whitney $U$-test. SLC20A1 mRNA expression was also plotted using paired comparison of normal versus cancer tissue with samples for which there were SLC20A1 mRNA data from both normal and cancer tissues from the same patients $(n=60)$. The $p$-value was calculated using the Wilcoxon signed-rank test. We set the level of significance at 5\%, two sided. All statistical analyses were carried out using BellCurve for Excel ver. 3.00 (SSRI, Tokyo, Japan).

Analysis of the Molecular Taxonomy of Breast Cancer International Consortium dataset. The Molecular Taxonomy of Breast Cancer International Consortium (METABRIC) dataset $(44,45)$ was downloaded from the cBioportal $(46,47)$ on July 29, 2020. The clinicopathological data from these patients have been summarized previously (34). The METABRIC dataset contains data on both gene alterations $(n=2173)$ and mRNA expression levels $(n=1904)$. The mRNA expression levels were compared using the Kruskal-Wallis and Steel-Dwass multiple comparison test. We defined the optimal cutoff thresholds to divide patients into high- and low-expression groups using receiver operator characteristic (ROC) curves relating SLC20A1 expression gene to disease-specific survival (DSS). The optimal cutoff threshold was determined using the Youden index. The $\chi^{2}$ test was performed to assess the correlation between clinicopathologic parameters and SLC20A1 expression levels. Survival curves based on DSS, were plotted using the Kaplan-Meier method, and curves were compared using the log-rank (CochranMantel-Haenszel) test. A multivariate Cox regression analysis was used to evaluate the influence of gene expression and to estimate adjusted hazard ratios (HRs) using DSS statuses. We set the level of significance at 5\%, two sided. All statistical analyses were carried out using BellCurve for Excel ver. 3.00 (SSRI, Tokyo, Japan).

Analysis of the DNA methylation using UALCAN. Levels of SLC20A1 DNA methylation at the CpG island in the promoter region were analyzed using UALCAN (48). The Beta values indicate the DNA methylation level: Beta values of 0.7-0.5 indicate hypermethylation, while Beta values of $0.3-0.25$ indicate hypomethylation.

Cell culture. Human claudin-low type (MDA-MB 231) and basallike type (MDA-MB 468) breast cancer cell lines $(6,49,50)$ were cultured in Dulbecco's modified Eagle's medium (DMEM) containing $10 \%$ fetal bovine serum (FBS) (Capricorn, Ebsdorfergrund, Germany). Human luminal A type (MCF-7) cells $(6,49,50)$ were cultured in DMEM containing 10\% FBS and 0.01 $\mathrm{mg} / \mathrm{ml}$ insulin. MDA-MB 231, MDA-MB 468 and MCF-7 cells were all obtained from the American Type Culture Collection (ATCC, Manassas, VA, USA). Mycoplasma testing was performed for the cell lines used.

siRNA transfection. For WST-8 assays, SLC20A1 knockdown (KD) was accomplished by transfection of two siRNAs: siRNA-1 (5'-CUC UAG UGG CUU CAG UAU UTT-3') and siRNA-2 (5'-GAA UUC GAA UGG ACA GUU ATT-3') (Sigma-Aldrich, St. Louis, MO, USA). For tumor-sphere culture, SLC20A1 KD in MDA-MB 231 and MDAMB 468 cells was accomplished by transfection with the DsiRNA sense strand (5'-CUCUAGUGGCUUCAGUAUUGAACTG-3') and antisense strand (5'-CAGUUCAAUACUGAAGCCACUAGAGGG3') (IDT, Coralville, IA, USA), which results in long term suppression of gene expression (51). As controls, we used MISSION siRNA Universal Negative Control (Sigma-Aldrich) and Negative Control DsiRNA (IDT), respectively. The transfection was accomplished using siRNA mixed OPTI-MEM (Gibco, Thermo Fisher, Waltham, MA, USA) and Lipofectamine ${ }^{\mathrm{TM}}$ RNAiMAX Transfection Reagent (Invitrogen). KD efficiency was monitored using Quantitative PCR as 
previously described (52) (SLC20A1 probe, 5'-/FAM/TTAGGCA ACTGCACTGCACCATTCACGG/TAMRA/-3'; forward primer, 5'GCGTGGACTTGAAAGAGGAAAC-3'; reverse primer, 5'-CTGAC GGCTTGACTGAACTGG-3').

WST-8 assay. WST-8 assay was performed as previously described $(34,53,54)$. Briefly, following transfection of $10 \mathrm{nM}$ siRNA, the cells were incubated for $24 \mathrm{~h}$. Then, they were seeded into 96-well plates $\left(5 \times 10^{3}\right.$ cells/well) (Thermo Fisher) and incubated for an additional $24 \mathrm{~h}$. Cell viability was then assessed using Cell Counting Reagent SF (Nacalai tesque, Kyoto, Japan). The formazan dye formed was measured using Sunrise Remote (TECAN, Seestrasse, Männedorf, Switzerland) at $450 \mathrm{~nm}$. Statistical significance was determined with Student's $t$-test, $* * p<0.01, * p<0.05$. Data are presented as means $\pm \mathrm{SE}$ of three independent experiments.

Tumor-sphere culture. Tumor-sphere formation was assayed as described previously $(34,52-54)$. Following transfection of $10 \mathrm{nM}$ DsiRNA, MDA-MB 231 and MDA-MB 468 cells were cultured for 48 h. Then, ALDH1 high cells were isolated from the DsiRNA transfectants using an ALDEFLUOR assay kit (Stem Cell Technologies, Vancouver, British Columbia, Canada) with a FACS Aria $^{\mathrm{TM}}$ III (BD Bioscience, San Jose, CA, USA). The FACS data were analyzed using Flowjo v10.6 software (BD Bioscience). The isolated ALDH 1 high cells were plated in ultralow attachment 96-well plates (Greiner Bio-One, Kremsmünster, Austria) at a density of $1 \times 10^{3}$ cells/well and cultured for 7 days in MDA-MB 231 and MDA-MB 468 culture medium containing $0.6 \%$ methylcellulose (Nacalai tesque, Kyoto, Japan) and $0.05 \mathrm{mM}$ 2-mercaptoethanol (Sigma-Aldrich). For each sample, four images per well from 3 wells were randomly captured using a DMIL LED (Leica, Wetzlar, Germany). The number and size of tumor spheres over $314 \mu \mathrm{m}^{2}$ were then measured using ImageJ Fiji software.

\section{Results}

SLC20A1 is more highly expressed in breast cancer than normal mammary epithelium. We first compared the levels of SLC20A1 expression in normal breast and breast cancer tissues in TCGA breast cancer $(n=593)$ dataset downloaded from the Oncomine database (43). As shown in Figure 1A, SLC20A1 expression was higher in breast cancer than in normal mammary epithelium. Paired comparison of SLC20A1 mRNA expression between normal and tumor tissues derived from the same patients further confirmed that SLC20Al expression is higher in breast cancer than normal mammary epithelium (Figure 1B).

We next examined SLC20Al expression among breast cancer subtypes using both TCGA and the METABRIC datasets $(44,45)$. Analyzed in TCGA dataset were data from normal tissues and breast cancer subtypes classified based on IHC. As shown in Figure 1C, SLC20Al expression was higher in all subtypes than in normal tissues. Analyzed in the METABRIC dataset were data from breast cancer subtypes classified based on IHC or PAM50. Among subtypes classified based on IHC, SLC20Al expression was higher in the HER2+ subtypes (ER+ and/or PgR+ HER2+ subtype, ER- and PgR- HER2+ subtype) (Figure 1D). In addition, among subtypes classified based on PAM50, SLC20Al was more highly expressed in the luminal B and HER2-enriched subtypes (Figure 1E).

These results suggest that $S L C 20 A 1$ is highly expressed in breast cancer. For that reason, we assessed SLC20A1 gene alterations using the METABRIC dataset from the cBioportal database as well as SLC20A1 DNA methylation using UALCAN (48). SLC20A1 gene amplification was detected in only $0.32 \%$ of breast cancers $(7 / 2173)$, and other gene mutations, including deep deletion, point mutation and fusion, were undetected. In addition, the frequency of DNA methylation was lower in breast cancer than in normal tissue; Beta values, which indicate the level of DNA methylation, were very low (Normal: median, 0.048; Cancer: median, 0.045). Moreover, very little DNA methylation was detected at the CpG island in the promoter region of SLC2OAl (Figure $1 F)$. These results suggest the high level of SLC20A1 mRNA expression seen in breast cancer as compared to normal tissues reflects the transcriptional activation of $S L C 20 A 1$ rather than a change in DNA methylation or gene amplification.

Kaplan-Meier analyses indicate that clinical outcomes are poor for SLC20A1 $I^{\text {high }}$ patients with ER+ luminal A and B types or the claudin-low or basal-like breast cancers. Our earlier analysis of TCGA dataset $(n=526)$ revealed that patients with SLC20A1 ${ }^{\text {high }} \mathrm{ER}+$ breast cancers had poor clinical outcomes (41). However, the number of patients in the cohort was small, and the role of SLC20A1 in breast cancer subtypes other than the ER+ type remained unknown. In the present study, therefore, to assess the role of SLC20A1 expression in other breast cancer subtypes, we analyzed a METABRIC dataset that included the gene expression data from 1904 breast cancer patients. The relationship between SLC20A1 expression and clinicopathologic parameters was examined using the $\chi^{2}$ test, which revealed that $S L C 20 A 1$ expression did not correlate with age $(p=0.80)$, tumor size $(p=0.10)$, tumor stage $(p=0.36)$ or lymph node metastasis $(p=0.41)$. The association between SLC20A1 expression and prognosis among the breast cancer subtypes was examined by using the Kaplan-Meier method to compare DSS between SLC2OAl high and SLC20Al ${ }^{\text {low }}$ patients. Among breast cancer subtypes classified with IHC, only SLC20A1 $1^{\text {high }}$ patients with the ER+ and/or PgR+ HER2subtype showed poor prognosis $(p<0.001$; Figure 2$)$. Among breast cancer subtypes classified based on PAM50, SLC20Al ${ }^{\text {high }}$ patients with luminal A or B, which were ER+ (luminal A: $p<0.001$; luminal B: $p=0.026$ ) had poor prognosis (Figure $3 \mathrm{C}$ and D). Importantly, SLC20Al $l^{\text {high }}$ patients with the claudin-low or basal-like type also had poor prognosis (claudin-low: $p=0.0054$; basal-like: $p<0.001$ ) (Figure 3F and $\mathrm{G})$. On the other hand, SLC20Al ${ }^{\text {high }}$ patients with the normallike type did not show poor prognosis $(p=0.095)$ (Figure 3B), and SLC2OAI $I^{\text {high }}$ patients with the HER2-enriched type had good prognosis $(p=0.0021)$ (Figure 3E). 

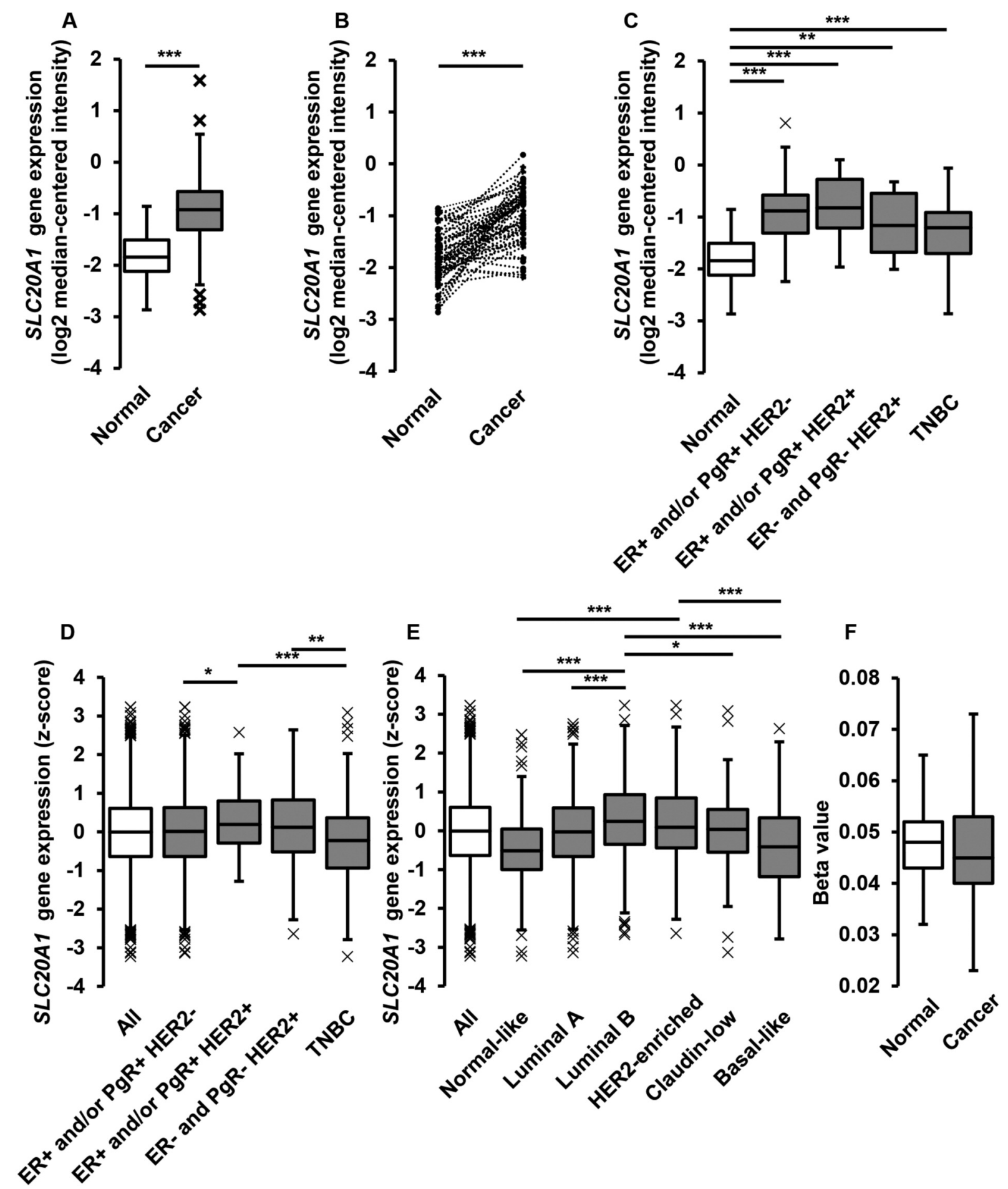

Figure 1. SLC20A1 is highly expressed in breast cancer. (A-C) SLC20A1 mRNA expression in normal mammary epithelium and breast cancer. TCGA breast data was downloaded from Oncomine. (A) Box plots showing SLC20A1 mRNA levels in normal mammary epithelium ( $n=61$ ) and all breast cancers ( $n=532$ ). $*_{* *}^{*}<0.001$, two-sided Mann-Whitney's U test. (B) Paired comparison of SLC20A1 mRNA expression in normal and tumor tissues from the same patients $(n=60) . * * * p<0.001$, Wilcoxon signed rank test. (C) Boxplots showing SLC20A1 mRNA levels in normal tissues and breast cancer subtypes classified based on IHC. ${ }^{* *} p<0.001, * * p<0.01$, Kruskal-Wallis test with Steel-Dwass test. (D, E) SLC20A1 mRNA expression in breast cancer subtypes. For this analysis, METABRIC data was downloaded from cBioportal. (D) IHC subtypes (E) PAM50 subtypes. ***p $<0.001$, **p $<0.01$, *p<0.05 Kruskal-Wallis and Steel-Dwass multiple comparison test. $(F)$ Box plots showing SLC20A1 DNA methylation levels determined using UALCAN in normal ( $n=97)$ and breast cancer (n=793). The Beta values indicate the DNA methylation levels (hypermethylation, Beta values=0.7-0.5; hypomethylation, Beta values=0.3-0.25). 
A

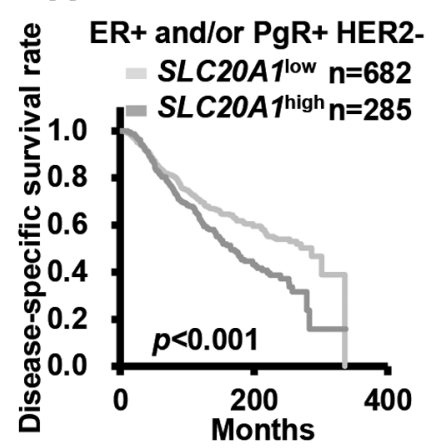

B

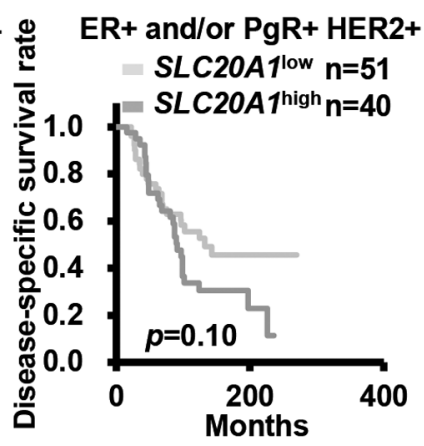

C

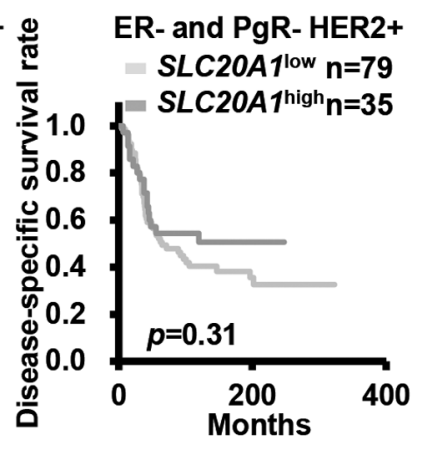

D

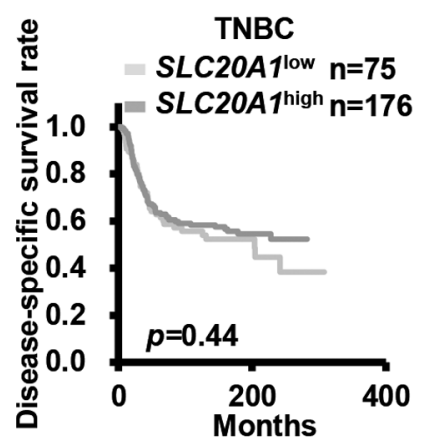

Figure 2. Kaplan-Meier analyses of disease-specific survival show that SLC20A1 high patients with ER+and/or PgR+ HER2- type breast cancers have poor clinical outcomes. (A-D) Kaplan-Meier analyses comparing disease-specific survival between SLC20A1 high and SLC20A1low patients in the METABRIC dataset: (A) ER+ and/or PgR+HER2-, (B) ER+ and/or PgR+HER2+, (C) ER-and PgR- HER2+, (D) TNBC subtypes. p-Values were calculated with the log-rank (Cochran-Mantel-Haenszel) test. SLC20A1 high patients are shown with a dark gray line, SLC20A1low patients with a light gray line.

Multivariate Cox regression analysis confirms that SLC20A1 ${ }^{\text {high }}$ breast cancer patients with the ER+ luminal A or B subtypes or the claudin-low or basal-like subtypes have poorer clinical outcomes. To confirm the results by KaplanMeier analyses, we performed a multivariate Cox regression analysis of DSS using the same dataset (Table I). As with the Kaplan-Meier analysis, SLC20A1 $1^{\text {high }}$ patients with the luminal A or B subtype (luminal A: HR=1.69, 95\%CI=1.212.37; luminal $\mathrm{B}: \mathrm{HR}=1.65,95 \% \mathrm{CI}=1.08-2.54)$ or the claudinlow or basal-like subtype (claudin-low: $\mathrm{HR}=2.34$, 95\% $\mathrm{CI}=1.28-4.25$; basal-like: $\mathrm{HR}=2.19,95 \% \mathrm{CI}=1.38-3.46$ ) showed poorer prognosis. SLC2OAl ${ }^{\text {high }}$ patients with the normal-like subtype did not show poor prognosis $(\mathrm{HR}=0.57$, 95\% CI=0.28-1.15), and those with the HER2-enriched subtype showed good prognosis $(\mathrm{HR}=0.44,95 \% \mathrm{CI}=0.26-$ $0.75)$. These results strongly suggest that $S L C 20 A I^{\text {high }}$ is involved in cancer progression and contributes to poor clinical outcomes in breast cancer patients with ER+, claudin-low and basal-like breast cancers.

Chemotherapy was not associated with poorer clinical outcomes in SLC20AI ${ }^{\text {high }}$ patients with claudin-low or basallike breast cancer. Because chemotherapy is the primary treatment for claudin-low and basal-like breast cancers (15, 16), we investigated the association between SLC20Al expression and chemotherapy in claudin-low and basal-like breast cancer (claudin-low without chemotherapy, $n=130$; claudin-low with chemotherapy, $n=69$; basal-like without chemotherapy, $n=91$; basal-like with chemotherapy, $n=108$ ). Both Kaplan-Meier and multivariate Cox regression analyses showed that SLC20AI high patients treated without chemotherapy had poorer prognosis than SLC20A1 ${ }^{\text {low }}$ patients (KM: claudin-low: $p<0.001$; basal-like: $p<0.001$ ) (COX: claudin-low: $\quad \mathrm{HR}=3.73, \quad 95 \% \mathrm{CI}=1.80-7.76$; basal-like: $\mathrm{HR}=4.97,95 \% \mathrm{CI}=2.39-10.36$ ) (Figure 4A and B, Table I). By contrast, among patients treated with chemotherapy, the prognosis of $S L C 2 O A I^{\text {high }}$ patients were no poorer than those of SLC2OAI ${ }^{\text {low }}$ patients (KM: claudin-low: $p=0.54$; basal-like: $p=0.20$ ) (COX: claudin-low: $\mathrm{HR}=0.80,95 \% \mathrm{CI}=0.34-1.86$; basal-like: $\mathrm{HR}=1.39,95 \% \mathrm{CI}=0.78-2.47$ ) (Figure 4C and D, Table I). Multivariate Cox regression analysis revealed that adding radiotherapy to chemotherapy as a covariate was associated with a poor prognosis (No chemotherapy: claudinlow: $\mathrm{HR}=3.81$, 95\% $\mathrm{CI}=1.84-7.92$; basal-like: $\mathrm{HR}=4.86$, 95\% CI=2.32-10.18) (Chemotherapy: claudin-low: $\mathrm{HR}=0.79$, 95\% CI=0.34-1.85; basal-like: $\mathrm{HR}=1.33,95 \% \mathrm{CI}=0.74-2.37$ ) (Table I). These results suggest that chemotherapy is an effective treatment against the claudin-low and basal-like types of SLC2OAl ${ }^{\text {high }}$ breast cancer.

Radiotherapy was associated with poorer clinical outcomes in SLC20A1 high patients with claudin-low or basal-like breast cancer. Because radiotherapy is also used in the treatment of breast cancer, we investigated the association between SLC20A1 expression and radiotherapy in patients with claudin-low or basal-like breast cancer (claudin-low without radiotherapy, $n=59$; claudin-low with radiotherapy, $n=140$; basal-like without radiotherapy, $\mathrm{n}=64$; basal-like with radiotherapy, $\mathrm{n}=135)$. Both Kaplan-Meier and multivariate Cox regression analyses showed that $S L C 20 A I^{\text {high }}$ patients with claudin-low breast cancer treated without radiotherapy had poorer prognoses than SLC20A1 ${ }^{\text {low }}$ patients (KM: claudinlow, $p=0.037, \mathrm{HR}=3.39$, 95\% $\mathrm{CI}=1.07-10.71$; basal-like: $p=0.079$ ) (KM: claudin-low, $p=0.037$; basal-like, $p=0.079$ ) (COX: claudin-low, $\mathrm{HR}=3.39,95 \% \mathrm{CI}=1.07-10.71$; basal-like, $\mathrm{HR}=1.86$, 95\%CI 0.87-4.00) (Figure 4E and F, Table I). 

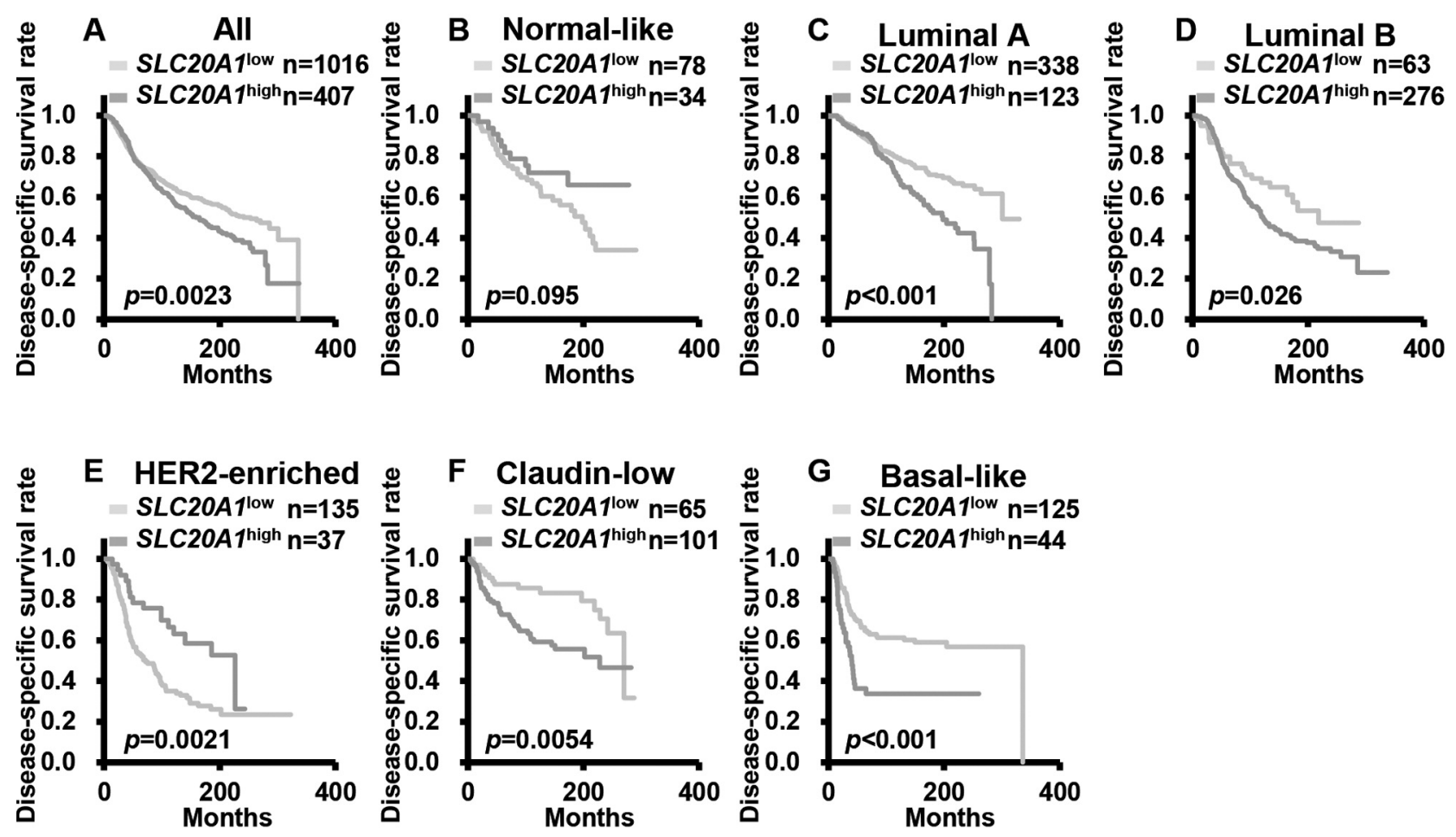

Figure 3. Kaplan-Meier analyses of disease-specific survival show that SLC20A1 high patients with claudin-low and basal-like type breast cancers have poor clinical outcomes. (A-G) Kaplan-Meier analyses comparing disease-specific survival between SLC20A1 high and SLC20A1 low patients in the METABRIC dataset: $(A)$ all, $(B)$ normal-like, $(C)$ luminal $A,(D)$ luminal B, $(E)$ HER2-enriched, $(F)$ claudin-low, $(G)$ basal-like subtypes. $p$ Values were calculated with the log-rank (Cochran-Mantel-Haenszel) test. SLC2OAl high patients are shown with a dark gray line, SLC2OAl low patients with a light gray line.

Moreover, SLC20A $I^{\text {high }}$ patients with claudin-low or basallike breast cancers treated with radiotherapy had poorer prognosis than $S L C 20 A I^{\text {low }}$ patients treated with radiotherapy (KM: claudin-low, $p=0.039$; basal-like, $p=0.0011$ ) (COX: claudin-low, $\quad \mathrm{HR}=2.12, \quad 95 \% \mathrm{CI}=1.03-4.37$; basal-like, $\mathrm{HR}=2.46$, 95\% CI=1.37-4.42) (Figure 4G and H, Table I). Multivariate Cox regression analysis revealed that addition of chemotherapy as a covariate was also associated with a poor prognosis (No radiotherapy: claudin-low, $\mathrm{HR}=3.73$, 95\%CI=1.16-11.98; basal-like, $\mathrm{HR}=1.89,95 \% \mathrm{CI}=0.88-4.06$ ) (Radiotherapy: claudin-low, $\mathrm{HR}=2.45,95 \% \mathrm{CI}=1.18-5.10$; basal-like, $\mathrm{HR}=2.37$, 95\%CI=1.31-4.27) (Table I). These results strongly suggest that unlike chemotherapy, radiotherapy is not an effective treatment for $S L C 20 A l^{\text {high }}$ patients with claudin-low or basal-like breast cancer.

SLC20A1 siRNA knockdown leads to suppression of MCF7, MDA-MB 231 and MDA-MB 468 cell viability. Given the results summarized in the previous sections, we investigated the possibility that SLC20A1 could serve as a therapeutic target for the treatment of claudin-low and basal-like breast cancers. WST-8 cell viability assays with MCF-7 (luminal A type), MDA-MB 231 (claudin-low type) and MDA-MB 468 (basal-like type) cells showed that SLC20A1 KD using targeted siRNA suppressed cell viability in all three lines (Figure 5A-C). This suggests SLC20A1 contributes to cancer cell survival/proliferation in claudin-low, basal-like and ER+ breast cancer subtypes. Moreover, SLC20A1 could be a therapeutic target as well as a prognostic marker in these cancers.

SLC20A1 siRNA knockdown leads to suppression of in vitro tumor-sphere formation by ALDH1 $1^{\text {high }}$ cells. To assess the role of SLC20A1 in ALDH1+ CSCs, we used ALDEFLUOR assays to examine the effects of SLC20A1 depletion in ALDH1 ${ }^{\text {high }}$ MDA-MB 231 and MDA-MB 468 cells on tumor-sphere formation. SLC20A1 KD led to a decrease in $\mathrm{ALDH} 1^{\text {high }}$ cell numbers and suppression of in vitro tumorsphere formation by ALDH1 ${ }^{\text {high }}$ MDA-MB 231 and MDAMB 468 cells (Figure 5D-K). These results suggest that SLC20A1 is essential for tumor formation by ALDH1+ breast CSCs in claudin-low and basal-like breast cancers. 


\section{Discussion}

In this study, we revealed that $S L C 20 A 1$ is more highly expressed in breast cancer than normal tissue (Figure 1A and B) and that high SLC20Al expression contributes to poor prognosis in ER+ (luminal A or B), claudin-low and basallike breast cancers (Figure 3, Table I). SLC2OAl ${ }^{\text {high }}$ patients with claudin-low or basal-like breast cancers treated with chemotherapy did not have poorer clinical outcomes than SLC20Al ${ }^{\text {low }}$ patients (Figure 4C and D, Table I). However, $S L C 20 A l^{\text {high }}$ patients treated with radiotherapy did have poorer clinical outcomes (Figure $4 \mathrm{G}$ and H, Table I). In addition, SLC20A1 depletion suppressed both the viability of ER+ (luminal A), claudin-low and basal-like cancer cells and in vitro tumor-sphere formation by ALDH1 $1^{\text {high }}$ cells (Figure 5).

SLC20A1 gene amplification was detected in only $0.32 \%$ of breast cancers (7/2173), and no other gene deep deletion, mutation or fusion was detected. A very low frequency of DNA methylation was detected at the $\mathrm{CpG}$ island of the SLC20A1 promoter in breast cancer (Figure 1F). It is therefore thought that transcriptional regulation is important for the high SLC20Al expression seen in breast cancer, and it is anticipated that future study will reveal the transcriptional mechanism.

SLC20A1 is highly expressed in luminal B and HER2enriched breast cancer subtypes (Figure 1C-E). Interestingly, unlike $S L C 20 A I^{\text {high }}$ patients with luminal A/B, claudin-low, or basal-like breast cancers, those with the HER2-enriched type have good prognosis (Figure 3, Table I). Among patients with luminal B breast cancers, only about $20 \%$ are HER2+ (9). Thus, in SLC20A1 ${ }^{\text {high }}$ patients with luminal B type cancers, the poor prognosis may not be associated with HER2 expression. The role of SLC20A1 in the HER2enriched subtype and its contribution to a good prognosis remains to be determined.

Because there are few molecular targeted drugs against claudin-low and basal-like breast cancer subtypes, the primary treatments consist of surgery, chemotherapy and radiotherapy $(13,15,16)$. Although many claudin-low type tumors overlap with TNBC $(12,13)$, ER is also expressed in some claudin-low type (55), and $46.7 \%$ of claudin-low type patients $(93 / 199)$ are not classified into TNBC. Therefore, the role of SLC20A1 in the reclassification of claudin-low type needs to be examined. Clinical outcomes of SLC20A1 ${ }^{\text {high }}$ patients treated with chemotherapy are as good as those of $S L C 20 A I^{\text {low }}$ patients treated with chemotherapy, which is in contrast to patients treated without chemotherapy (Figure 4A-D, Table I). Thus, chemotherapy is an effective treatment for $S L C 20 A I^{\text {high }}$ patients with claudin-low or basal-like breast cancer.

On the other hand, SLC20A1 ${ }^{\text {high }}$ patients treated with radiotherapy showed poorer clinical outcomes than
Table I. Multivariate Cox proportional regression hazards model analyses of SLC2OAI high patients' prognoses in each subtype and without/with chemo- and radiotherapy in claudin-low and basal-like types.

\begin{tabular}{|c|c|c|c|}
\hline & Hazard ratio & $\begin{array}{c}95 \% \text { confidence } \\
\text { interval }\end{array}$ & $p$-Value \\
\hline & \multicolumn{3}{|c|}{ DSS } \\
\hline All & $1.26 *$ & $1.07-1.49$ & 0.0061 \\
\hline Normal-like & $0.57 *$ & $0.28-1.15$ & 0.12 \\
\hline Luminal A & $1.69 *$ & $1.21-2.37$ & 0.0022 \\
\hline Luminal B & $1.65 *$ & $1.08-2.54$ & 0.022 \\
\hline HER2-enriched & $0.44 *$ & $0.26-0.75$ & 0.003 \\
\hline Claudin-low & $2.34 *$ & $1.28-4.25$ & 0.0054 \\
\hline Basal-like & $2.19^{*}$ & $1.38-3.46$ & $<0.001$ \\
\hline \multicolumn{4}{|c|}{ Without chemotherapy } \\
\hline Claudin-low & $3.73 *$ & $1.80-7.76$ & $<0.001$ \\
\hline Basal-like & $4.97 *$ & $2.39-10.36$ & $<0.001$ \\
\hline \multicolumn{4}{|c|}{ With chemotherapy } \\
\hline Claudin-low & $0.80 *$ & $0.34-1.86$ & 0.60 \\
\hline Basal-like & $1.39 *$ & $0.78-2.47$ & 0.27 \\
\hline \multicolumn{4}{|c|}{ Without chemotherapy } \\
\hline Claudin-low & $3.81 * *$ & $1.84-7.92$ & $<0.001$ \\
\hline Basal-like & $4.86^{* *}$ & $2.32-10.18$ & $<0.001$ \\
\hline \multicolumn{4}{|c|}{ With chemotherapy } \\
\hline Claudin-low & $0.79 * *$ & $0.34-1.85$ & 0.58 \\
\hline Basal-like & $1.33 * *$ & $0.74-2.37$ & 0.34 \\
\hline \multicolumn{4}{|c|}{ Without radiotherapy } \\
\hline Claudin-low & $3.39 *$ & $1.07-10.71$ & 0.038 \\
\hline Basal-like & $1.86^{*}$ & $0.87-4.00$ & 0.11 \\
\hline \multicolumn{4}{|c|}{ With radiotherapy } \\
\hline Claudin-low & $2.12 *$ & $1.03-4.37$ & 0.040 \\
\hline Basal-like & $2.46^{*}$ & $1.37-4.42$ & 0.0025 \\
\hline \multicolumn{4}{|c|}{ Without radiotherapy } \\
\hline Claudin-low & $3.73 * * *$ & $1.16-11.98$ & 0.027 \\
\hline Basal-like & $1.89^{* * *}$ & $0.88-4.06$ & 0.10 \\
\hline \multicolumn{4}{|c|}{ With radiotherapy } \\
\hline Claudin-low & $2.45 * * *$ & $1.18-5.10$ & 0.016 \\
\hline Basal-like & $2.37 * * *$ & $1.31-4.27$ & 0.0041 \\
\hline
\end{tabular}

Hazard ratio; *adjusted by age; **adjusted by age and radiotherapy; ***adjusted by age and chemotherapy estimated using Cox proportional hazard model.

$S L C 20 A I^{\text {low }}$ patients treated with radiotherapy (Figure 4E-H, Table I). Unlike chemotherapy, radiotherapy is not an effective treatment for $S L C 20 A l^{\text {high }}$ patients with claudin-low or basallike breast cancer. It is known that there are radioresistant and insensitive types of breast cancer $(56,57)$; indeed, irradiation accelerates repopulation of tumor cells (18-20). Moreover, most CSCs have radioresistance and are origin of tumor recurrence $(22,24)$. ALDH1 activitiy may contribute to radioresistance of ALDH $1^{\text {high }}$ MDA-MB 231 and MDA-MB 468 breast cancer cells (24). Therefore, SLC20A1 targeted therapy may overcome radioresistance/insensitivity of CSCs. However, the relationship between SLC20Al function and radioresistance/insensitivity remains unknown. 

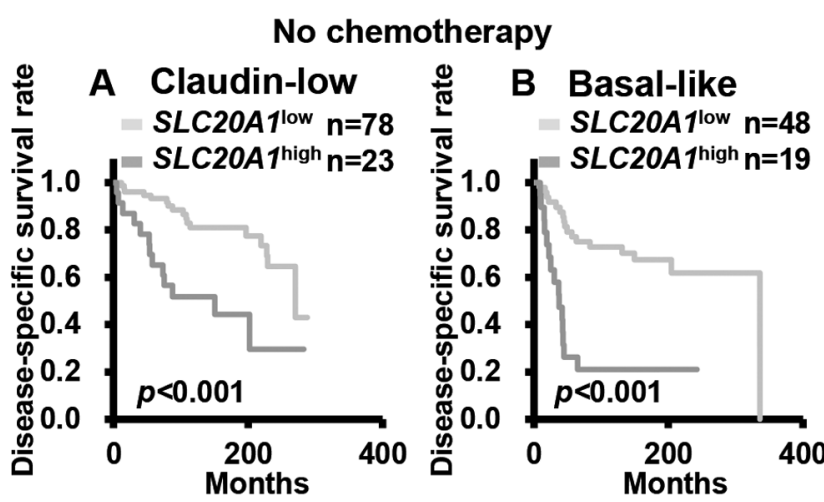

No radiotherapy
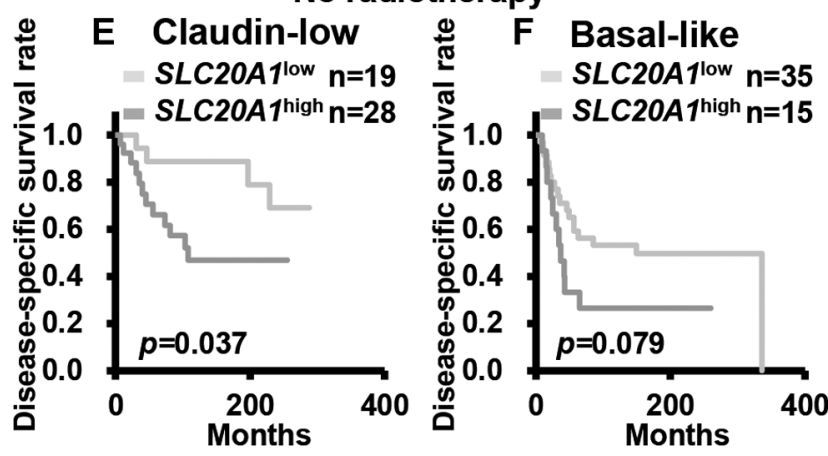

Chemotherapy
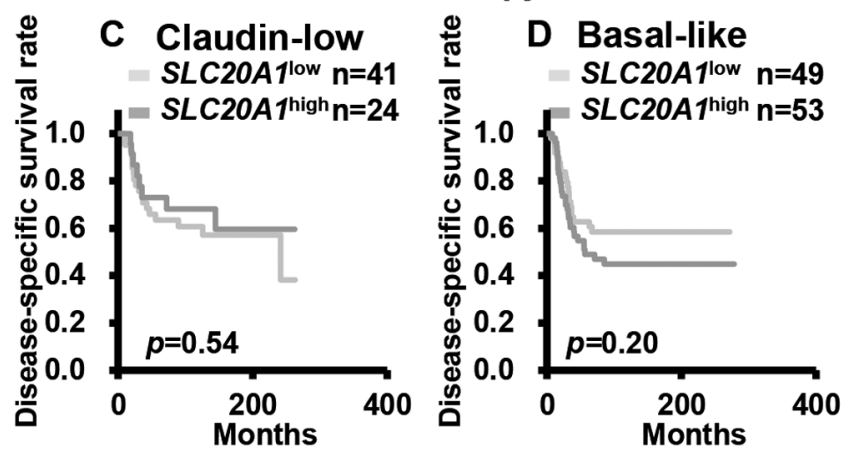

Radiotherapy
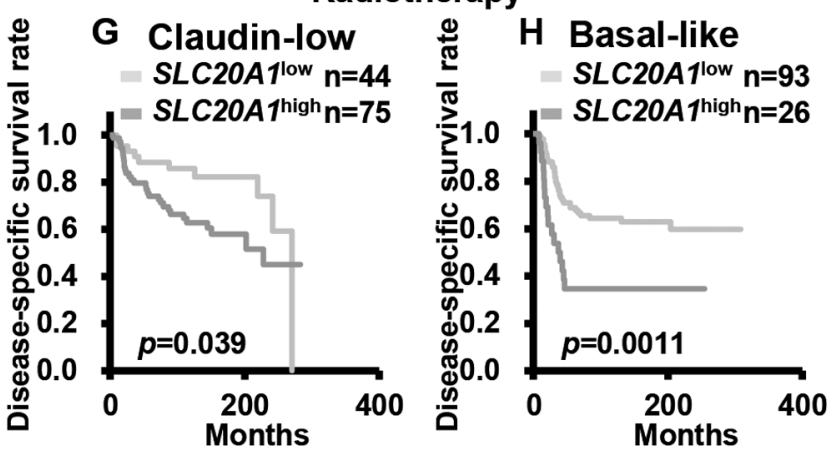

Figure 4. Kaplan-Meier analyses show that clinical outcomes of SLC20A1 high patients with claudin-low and basal-like breast cancers treated with chemotherapy are as good as those of SLC20A1 low patients, but outcomes of SLC20A1 high patients treated with radiotherapy are poorer. (A-H) Kaplan-Meier analyses comparing disease-specific survival between SLC20A1 high and SLC20Allow with claudin-low or basal-like breast cancer patients in the METABRIC dataset treated with or without chemotherapy or radiotherapy: (A) claudin-low without chemotherapy, (B) basal-like without chemotherapy, $(C)$ claudin-low with chemotherapy, $(D)$ basal-like with chemotherapy, $(E)$ claudin-low without radiotherapy, (F) basal-like without radiotherapy, $(G)$ claudin-low with radiotherapy, $(H)$ basal-like with radiotherapy.

In the treatment of breast cancer, chemotherapy and radiotherapy are usually part of a strict protocol that includes multiple cytotoxic drugs $(15,16)$. However, no details regarding the drugs administered, irradiation, or treatment term were available in the METABRIC dataset. At this point, therefore, there is a need to analyze the relationship between SLC20A1 expression and prognosis, considering the details of the chemo- and radiotherapeutic protocols.

SLC20A1-deficient mice exhibit defective liver development accompanied by decreased cell proliferation and increased cell death (37). A key function of SLC20A1 is mediating the uptake of Pi into cells $(35,36)$. In mouse embryonic fibroblasts, however, Pi uptake is not affected by SLC20A1-depletion (37), and SLC20A1 overexpression in MC3T3-E1 osteoblastic cells does not change Pi uptake (38). In addition, the introduction of Pi-uptake defective SLC20A1 (S128A) into SLC20A1-deficient cells restores cell viability (39). On the other hand, SLC20A1 reportedly contributes to cell proliferation and migration via the $\mathrm{Wnt} / \beta$-catenin signaling in GH3 somatotroph adenoma cells (40), and
SLC20A1 depletion in HeLa or HepG2 cells impairs their proliferation and suppresses tumor growth in HeLa xenografted mice (39). SLC20A1 depletion in HeLa cells leads to activation of p38 MAPK, but not ERK or JNK (39). It also sensitizes HeLa cells to TNF- $\alpha$-induced apoptosis via JNK signaling (58). It thus appears that SLC20A1 is involved in the regulation of Pi uptake-dependent and independent cell proliferation and death, though the mechanism remains to be determined.

Using information-theoretical analysis, we previously identified SLC2OAl expression as a poor prognosis marker in breast cancer (41). Based on the results of the genomic dataset analyses and in vitro experiments performed in the present study, we suggest that SLC20A1 could serve as a therapeutic target as well as a prognostic marker in ER+, claudin-low and basal-like breast cancers. Moreover, our findings reveal these types of analyses to be powerful methods with which to identify molecules with the potential to effectively serve as prognosis markers and/or molecular targets for the treatment of other forms of cancer. 
A

MCF-7 (Luminal A)

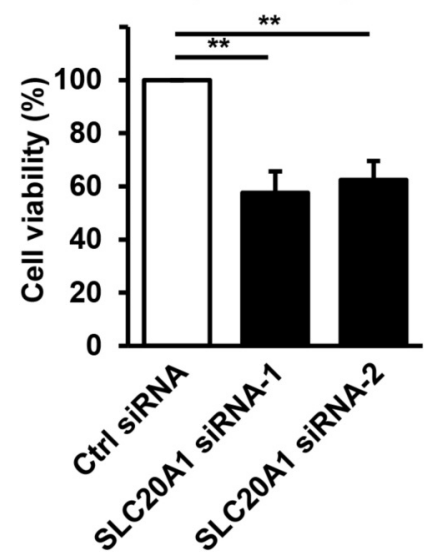

D

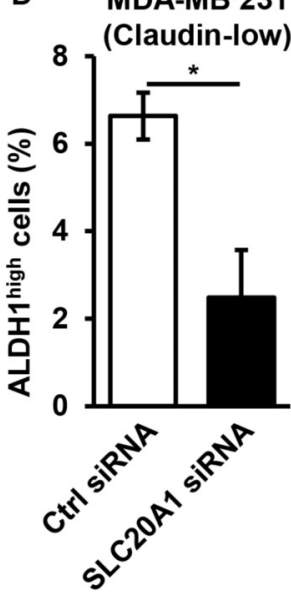

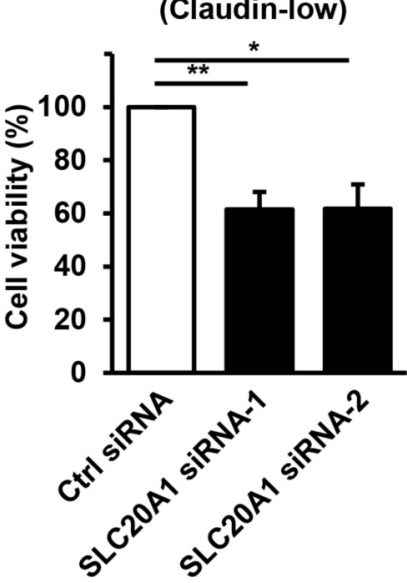

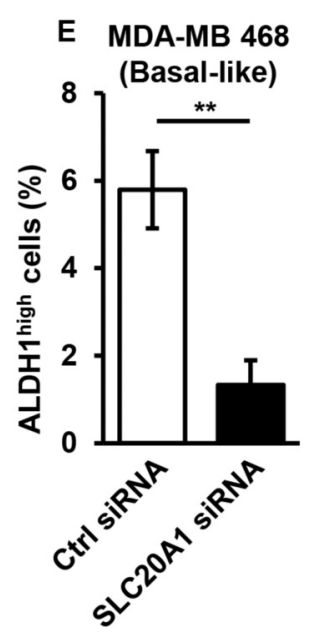

(Basal-like)
F MDA-MB 231

(Claudin-low)

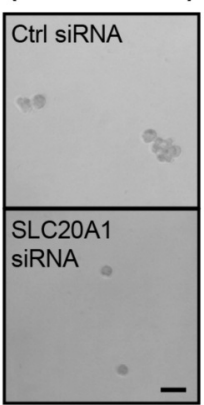

C

(Basal-like)

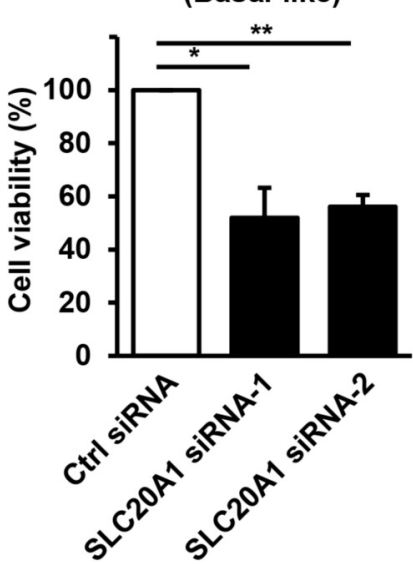

G MDA-MB 468

(Basal-like)

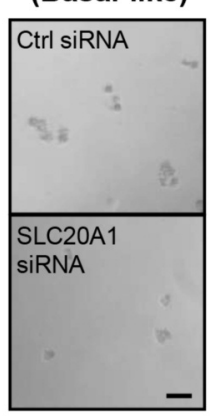

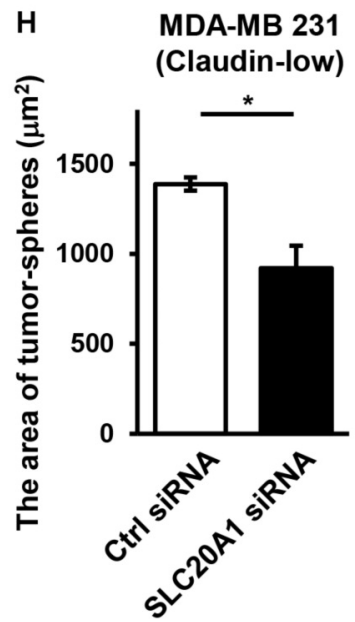
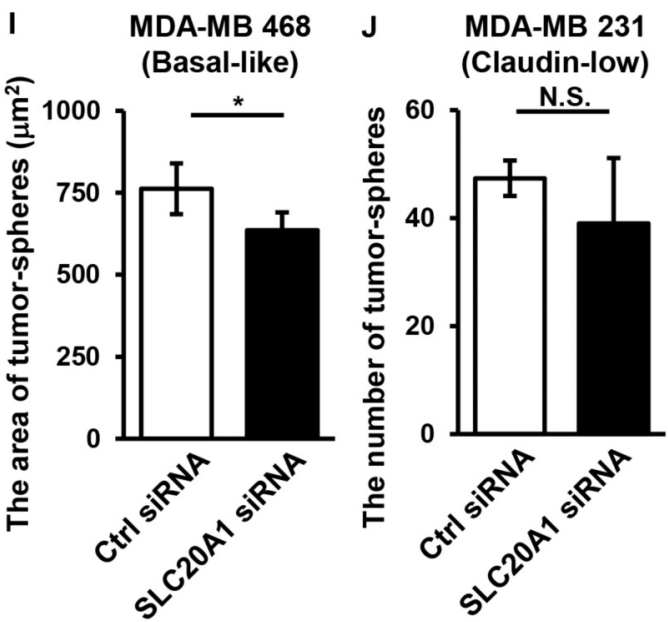

K MDA-MB 468

(Basal-like)

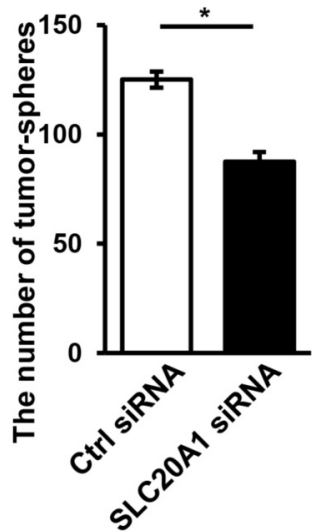

Figure 5. SLC20A1 knockdown using targeted siRNA suppresses the viability of MCF-7, MDA-MB 231, MDA-MB 468 cells and in vitro tumor-sphere formation by ALDHI high cells. (A-C) WST-8 assays assessing MCF-7 (A), MDA-MB 231 (B), MDA-MB 468 (C) cell viability 48 h after transfection of SLC2OAl-targeted siRNA. Values for the test groups are expressed relative to cells transfected with control siRNA. Bars represent means $\pm S E$ (three independent experiments). ${ }^{*} p<0.01,{ }^{*} p<0.05$. Student's t-test. (D-E) Numbers of ALDH1 high (D) MDA-MB 231 and (E) MDA-MB 468 cells. ${ }^{*} p<0.05$, ${ }^{* *} p<0.01$, Student's t-test. Bars represent means $\pm S D$ (three independent experiments). $(F-K)$ In vitro tumor-sphere formation by ALDH1 high,$M D A-M B 231$ and MDA-MB 468 cells (three independent experiments). Representative images are shown $(F-G)$, scale bar, $50 \mu m ;(H-I)$ areas of tumor-spheres, * $p<0.05$, Student's t-test, bars represent means $\pm S E$; and $(J-K)$ numbers of tumor-spheres, N.S.: Not significant, ${ }^{*} p<0.05$, Student's t-test, bars represent means $\pm S D$. 


\section{Conflicts of Interest}

The Authors declare that they have no competing interests in relation to this study.

\section{Authors' Contributions}

C.O., S.T., H.M., A.O., C.M. and Y.H. performed the experiments; C.O., S.T., H.M., A.O., C.M., I.M., and T.F. performed bioinformatics; Y.N., Y.H., Y.K., Y.H., T.S., Y.M., and K.S. supplied experimental materials and resources; C.O., S.T. and K.A. conceived the study; C.O., S.T. and K.A. drafted the manuscript; C.O., S.T., H.M., A.O., Y.H., Y.N., T.S., Y.M., K.S. and K.A. contributed to discussion and review of the final manuscript; all the authors approved the final manuscript.

\section{Acknowledgements}

The Authors are grateful to Mr. Yanagawa for help with the experiments. This work was supported by the MEXT-Supported Program for the Strategic Research Foundation at Private Universities (2014-2018). The research was supported by Grant-in-Aid for Scientific Research (C) of JSPS (20K07207) (K. A.) and Grant-in-Aid for JSPS Research Fellows (20J11980) (S. T.). Nagai Memorial Research Scholarship from the Pharmaceutical Society of Japan (H. M.).

\section{References}

1 Ferlay J, Colombet M, Soerjomataram I, Mathers C, Parkin DM, Piñeros M, Znaor A and Bray F: Estimating the global cancer incidence and mortality in 2018: GLOBOCAN sources and methods. Int J Cancer 144(8): 1941-1953, 2019. PMID: 30350310. DOI: 10.1002/ijc.31937

2 Van de Vijver MJ, He YD, van't Veer LJ, Dai H, Hart AA, Voskuil DW, Schreiber GJ, Peterse JL, Roberts C, Marton MJ, Parrish M, Atsma D, Witteveen A, Glas A, Delahaye L, van der Velde T, Bartelink H, Rodenhuis S, Rutgers ET, Friend SH and Bernards R: A gene-expression signature as a predictor of survival in breast cancer. N Engl J Med 347(25): 1999-2009, 2002. PMID: 12490681. DOI: 10.1056/NEJMoa021967

3 Perou CM, Sørlie T, Eisen MB, van de Rijn M, Jeffrey SS, Rees CA, Pollack JR, Ross DT, Johnsen H, Akslen LA, Fluge O, Pergamenschikov A, Williams C, Zhu SX, Lønning PE, Børresen-Dale AL, Brown PO and Botstein D: Molecular portraits of human breast tumours. Nature 406(6797): 747-752, 2000. PMID: 10963602. DOI: $10.1038 / 35021093$

4 Sørlie T, Perou CM, Tibshirani R, Aas T, Geisler S, Johnsen H, Hastie T, Eisen MB, van de Rijn M, Jeffrey SS, Thorsen T, Quist $\mathrm{H}$, Matese JC, Brown PO, Botstein D, Lønning PE and Børresen-Dale AL: Gene expression patterns of breast carcinomas distinguish tumor subclasses with clinical implications. Proc Natl Acad Sci USA 98(19): 10869-10874, 2001. PMID: 11553815. DOI: 10.1073/pnas.191367098

5 Herschkowitz JI, Simin K, Weigman VJ, Mikaelian I, Usary J, Hu Z, Rasmussen KE, Jones LP, Assefnia S, Chandrasekharan S, Backlund MG, Yin Y, Khramtsov AI, Bastein R, Quackenbush J, Glazer RI, Brown PH, Green JE, Kopelovich L, Furth PA, Palazzo JP, Olopade OI, Bernard PS, Churchill GA, Dyke TV and Perou CM: Identification of conserved gene expression features between murine mammary carcinoma models and human breast tumors. Genome Biol 8(5): R76, 2007. PMID: 17493263. DOI: $10.1186 / \mathrm{gb}-2007-8-5-\mathrm{r} 76$

6 Prat A, Parker JS, Karginova O, Fan C, Livasy C, Herschkowitz JI, He X and Perou CM: Phenotypic and molecular characterization of the claudin-low intrinsic subtype of breast cancer. Breast Cancer Res 12(5): R68, 2010. PMID: 20813035. DOI: $10.1186 / \mathrm{bcr} 2635$

7 Romero A, Prat A, García-Sáenz JA, Del Prado N, Pelayo A, Furió V, Román JM, de la Hoya M, Díaz-Rubio E, Perou CM, Cladés $\mathrm{T}$ and Martín M: Assignment of tumor subtype by genomic testing and pathologic-based approximations: implications on patient's management and therapy selection. Clin Transl Oncol 16(4): 386-394, 2014. PMID: 23907291. DOI: 10.1007/s12094-013-1088-Z

8 Gao JJ and Swain SM: Luminal A breast cancer and molecular assays: A review. Oncologist 23(5): 556-565, 2018. PMID: 29472313. DOI: 10.1634/theoncologist.2017-0535

9 Ades F, Zardavas D, Bozovic-Spasojevic I, Pugliano L, Fumagalli D, Azambuja E, Viale G, Sotiriou C and Piccart M: Luminal B Breast Cancer: Molecular characterization, clinical management, and future perspectives. J Clin Oncol 32(25): 2794-2803, 2014. PMID: 25049332. DOI: 10.1200/JCO.2013.54.1870

10 Wirapati P, Sotiriou C, Kunkel S, Farmer P, Pradervand S, Haibe-Kains B, Desmedt C, Ignatiadis M, Sengstag T, Schütz F, Goldstein DR, Piccart M and Delorenzi M: Meta-analysis of gene expression profiles in breast cancer: toward a unified understanding of breast cancer subtyping and prognosis signatures. Breast Cancer Res 10(4): R65, 2008. PMID: 18662380. DOI: $10.1186 / \mathrm{bcr} 2124$

11 Goldhirsch A, Winer EP, Coates AS, Gelber RD, Piccart-Gebhart M, Thürlimann B and Senn HJ: Personalizing the treatment of women with early breast cancer: highlights of the St Gallen International Expert Consensus on the Primary Therapy of Early Breast Cancer 2013. Ann Oncol 24(9): 2206-2223, 2013. PMID: 23917950. DOI: 10.1093/annonc/mdt303

12 Dias K, Dvorkin-Gheva A, Hallett RM, Wu Y, Hassell J, Pond GR, Levine M, Whelan T and Bane AL: Claudin-low breast cancer; clinical \& pathological characteristics. PLoS One 12(1): e0168669, 2017. PMID: 28045912. DOI: 10.1371/journal.pone.0168669

13 Badve S, Dabbs DJ, Schnitt SJ, Baehner FL, Decker T, Eusebi V, Fox SB, Ichihara S, Jacquemier J, Lakhani SR, Palacios J, Rakha EA, Richardson AL, Schmitt FC, Tan PH, Tse GM, Weigelt B, Ellis IO and Reis-Filho JS: Basal-like and triplenegative breast cancers: a critical review with an emphasis on the implications for pathologists and oncologists. Mod Pathol 24(2): 157-167, 2011. PMID: 21076464. DOI: 10.1038/modpathol.2010.200

14 Prat A, Pineda E, Adamo B, Galva'n P, Fern' andez A, Gaba L, Díez $\mathrm{M}$, Viladot M, Arance A and Mu noz M: Clinical implications of the intrinsic molecular subtypes of breast cancer. Breast 2: S26-35, 2015. PMID: 26253814. DOI: 10.1016/j.breast.2015.07.008

15 Waks AG and Winer EP: Breast cancer treatment: A review. JAMA 321(3): 288-300, 2019. PMID: 30667505. DOI: $10.1001 /$ jama.2018.19323

16 Balic M, Thomssen C, Würstlein R, Gnant M and Harbeck N: St. Gallen/Vienna 2019: A brief summary of the consensus discussion on the optimal primary breast cancer treatment. Breast Care 14(2): 103-110, 2019. PMID: 31798382. DOI: $10.1159 / 000499931$ 
17 Lønning PE, Sørlie T and Børresen-Dale AL: Genomics in breast cancer-therapeutic implications. Nat Clin Pract Oncol 2(1): 2633, 2005. PMID: 16264853 . DOI: $10.1038 /$ ncponc0072

18 Kim JJ and Tannock IF: Repopulation of cancer cells during therapy: an important cause of treatment failure. Nat Rev Cancer 5(7): 516-525, 2005. PMID: 15965493. DOI: $10.1038 / \mathrm{nrc} 1650$

$19 \mathrm{Ng}$ WL, Huang Q, Liu X, Zimmerman M, Li F and Li CY: Molecular mechanisms involved in tumor repopulation after radiotherapy. Transl Cancer Res 2(5): 442-448, 2013. PMID: 25599021. DOI: 10.3978/j.issn.2218-676X.2013.10.03

20 Phillips TM, McBride WH and Pajonk F: The response of CD24-/low/CD44+ breast cancer-initiating cells to radiation. J Natl Cancer Inst 98(24): 1777-1785, 2006. PMID: 17179479. DOI: $10.1093 /$ jnci/djj495

21 Idowu MO, Kmieciak M, Dumur C, Burton RS, Grimes MM, Powers CN and Manjili MH: CD44+/CD24-/low cancer stem/progenitor cells are more abundant in triple-negative invasive breast carcinoma phenotype and are associated with poor outcome. Hum Pathol 43(3): 364-373, 2012. PMID: 21835433. DOI: $10.1016 /$ j.humpath.2011.05.005

22 Visvader JE and Lindeman GJ: Cancer stem cells: current status and evolving complexities. Cell Stem Cell 10(6): 717-728, 2012. PMID: 22704512. DOI: 10.1016/j.stem.2012.05.007

23 Reya T, Morrison SJ, Clarke MF and Weissman IL: Stem cells, cancer, and cancer stem cells: Nature 414(6859): 105-111, 2001. PMID: 11689955. DOI: 10.1038/35102167

24 Croker AK and Allan AL: Inhibition of aldehyde dehydrogenase (ALDH) activity reduces chemotherapy and radiation resistance of stem-like ALDHhiCD44+ human breast cancer cells. Breast Cancer Res Treat 133(1): 75-87, 2012. PMID: 21818590. DOI: 10.1007/s10549-011-1692-y

25 Ginestier C, Hur MH, Charafe-Jauffret E, Monville F, Dutcher J, Brown M, Jacquemier J, Viens P, Kleer C, Liu S, Schott A, Hayes D, Birnbaum D, Wicha MS and Dontu G: ALDH1 is a marker of normal and malignant human mammary stem cells and a predictor of poor clinical outcome. Cell Stem Cell 1(5): 555-567, 2007. PMID: 18371393. DOI: 10.1016/j.stem.2007.08.014

26 Tanei T, Morimoto K, Shimazu K, Kim SJ, Tanji Y, Taguchi T, Tamaki Y, Noguchi S: Association of breast cancer stem cells identified by aldehyde dehydrogenase 1 expression with resistance to sequential paclitaxel and epirubicin-based chemotherapy for breast cancers. Clin Cancer Res 15(12): 4234-4241, 2009. PMID: 19509181. DOI: 10.1158/1078-0432.CCR-08-1479

27 Opdenaker LM, Arnold KM, Pohlig RT, Padmanabhan JS, Flynn DC and Sims-Mourtada J: Immunohistochemical analysis of aldehyde dehydrogenase isoforms and their association with estrogen-receptor status and disease progression in breast cancer. Breast Cancer 6: 205-209, 2014. PMID: 25540596. DOI: 10.2147/BCTT.S73674

28 Marcato P, Dwan CA, Pan DA, Araslanova R, Gillis M, Joshi M, Helyer L, Pan L, Leidal A, Gujar S, Giacomantonio CA and Lee PWK: Aldehyde dehydrogenase activity of breast cancer stem cells is primarily due to isoform ALDH1A3 and its expression is predictive of metastasis. Stem Cells 29(1): 32-45, 2011. PMID: 21280157. DOI: 10.1002/stem.563

29 Jiang F, Qiu Q, Khanna A, Todd NW, Deepak J, Xing L, Wang H, Liu Z, Su Y, Stass SA and Katz RL: Aldehyde dehydrogenase 1 is a tumor stem cell-associated marker in lung cancer. Mol Cancer Res 7(3): 330-338, 2009. PMID: 19276181. DOI: 10.1158/1541-7786.MCR-08-0393
30 Kim MP, Fleming JB, Wang H, Abbruzzese JL, Choi W, Kopetz S, McConkey DJ, Evans DB and Gallick GE: ALDH activity selectively defines an enhanced tumor-initiating cell population relative to $\mathrm{CD} 133$ expression in human pancreatic adenocarcinoma. PLoS One 6(6): e20636, 2011. PMID: 21695188. DOI: 10.1371/journal.pone.0020636

31 Su Y, Qiu Q, Zhang X, Jiang Z, Leng O, Liu Z, Stass SA and Jiang F: ALDH1A1 positive cell population is enriched in tumor-initiating cells and associated with progression of bladder cancer. Cancer Epidemiol Biomarkers Prev 19(2): 327-337, 2010. PMID: 20142235. DOI: 10.1158/1055-9965.EPI-09-0865

32 Landen Jr. CN, Goodman B, Katre AA, Steg AD, Nick AM, Stone RL, Miller LD, Mejia PV, Jennings NB, Gershenson DM,Bast Jr. RC, Coleman RL, Berestein GL and Sood AK: Targeting aldehyde dehydrogenase cancer stem cells in ovarian cancer. Mol Cancer Ther 9(12): 3186-3199, 2010. PMID: 20889728. DOI: 10.1158/1535-7163.MCT-10-0563

33 Marcato P, Dean CA, Liu RZ, Coyle KM, Bydoun M, Wallace M, Clements D, Turner C, Mathenge EG, Gujar SA, Giacomantonio CA, Mackey JR, Godbout $\mathrm{R}$ and Lee PEK: Aldehyde dehydrogenase 1A3 influences breast cancer progression via differential retinoic acid signaling. Mol Oncol 9(1): 17-31, 2015. PMID: 25106087. DOI: 10.1016/j.molonc.2014.07.010

34 Tamori S, Nozaki Y, Motomura H, Nakane H, Katayama R, Onaga C, Kikuchi E, Shimada N, Suzuki Y, Noike M, Hara Y, Sato K, Sato T, Yamamoto K, Hanawa T, Imai M, Abe R, Yoshimori Y, Takasawa R, Tanuma $\mathrm{S}$ and Akimoto $\mathrm{K}$ : Glyoxalase 1 gene is highly expressed in basal-like human breast cancers and contributes to survival of ALDH1-positive breast cancer stem cells. Oncotarget 9(92): 36515-36529, 2018. PMID: 30559934. DOI: 10.18632 /oncotarget.26369

35 Johann SV, Gibbons JJ and Oharai B: GLVR1, a receptor for Gibbon Ape Leukemia virus, is homologous to a phosphate permease of neurospora crassa and is expressed at high levels in the brain and thymus. J Virol 66(3): 1635-1640, 1992. PMID: 1531369. DOI: $10.1128 / J V I .66 .3 .1635-1640.1992$

36 Kavanaugh MP, Miller DG, Zhang W, Law W, Kozak SL, Kabat D and Miller AD: Cell-surface receptors for gibbon ape leukemia virus and amphotropic murine retrovirus are inducible sodiumdependent phosphate symporters. Proc Natl Acad Sci USA 91(15): 7071-7075, 1994. PMID: 8041748. DOI: 10.1073/pnas.91.15.7071

37 Beck L, Leroy C, Beck-Cormier S, Forand A, Salau“ n C, Paris $\mathrm{N}$, Bernier A, Ureña-Torres P, Prié D, Ollero M, Coulombel L and Friedlander G: The phosphate transporter PiT1 (Slc20a1) revealed as a new essential gene for mouse liver development. PLoS One 5(2): e9148, 2010. PMID: 20161774. DOI: 10.1371/journal.pone.0009148

38 Byskov K, Jensen N, Kongsfelt IB, Wielsøe M, Pedersen LE, Haldrup C and Pedersen L: Regulation of cell proliferation and cell density by the inorganic phosphate transporter PiT1. Cell Div 7(1): 7, 2012. PMID: 22394506. DOI: 10.1186/1747-1028-7-7

39 Beck L, Leroy C, Salau"n C, Margall-Ducos G, Desdouets C and Friedlander G: Identification of a novel function of PiT1 critical for cell proliferation and independent of its phosphate transport activity. J Biol Chem 284(45): 31363-31374, 2009. PMID: 19726692. DOI: $10.1074 /$ jbc.M109.053132

40 Li J, Dong W, Li Z, Wang H, Gao H and Zhang Y: Impact of SLC20A1 on the Wnt/ $\beta$-catenin signaling pathway in somatotroph adenomas. Mol Med Rep 20(4): 3276-3284, 2019. PMID: 31432167. DOI: 10.3892/mmr.2019.10555 
41 Sato K and Akimoto K: Expression levels of KMT2C and SLC20A1 identified by information-theoretical analysis are powerful prognostic biomarkers in estrogen receptor-positive breast cancer. Clin Breast Cancer 17(3): e135-142, 2017. PMID: 27986439. DOI: 10.1016/j.clbc.2016.11.005

42 Cancer Genome Atlas Network: Comprehensive molecular portraits of human breast tumors. Nature 490(7418): 61-70, 2012. PMID: 23000897. DOI: $10.1038 /$ nature 11412

43 Rhodes DI, Yu J, Shanker K, Deshpande N, Varambally R, Ghosh D, Barrette T, Pandeyb A and Chinnaiyan AM: ONCOMINE: A cancer microarray database and integrated datamining platform. Neoplasia 6(1): 1-6, 2004. PMID: 15068665. DOI: $10.1016 / \mathrm{s} 1476-5586(04) 80047-2$

44 Curtis C, Shah SP, Chin SF, Turashvili G, Rueda OM, Dunning MJ, Speed D, Lynch AG, Samarajiwa S, Yuan Y, Gräf S, Ha G, Haffari G, Bashashati A, Russell R, McKinney S, METABRIC Group, Langerød A, Green A, Provenzano E, Wishart G, Pinder S, Watson P, Markowetz F, Murphy L, Ellis I, Purushotham A, Børresen-Dale AL, Brenton JD, Tavaré S, Caldas C and Aparicio $\mathrm{S}$ : The genomic and transcriptomic architecture of 2,000 breast tumours reveals novel subgroups. Nature 486(7403): 346-52, 2012. PMID: 22522925. DOI: $10.1038 /$ nature 10983

45 Pereira B, Chin SF, Rueda OM, Vollan HK, Provenzano E, Bardwell HA, Pugh M, Jones L, Russell R, Sammut SJ, Tsui DW, Liu B, Dawson SJ, Abraham J, Northen H, Peden JF, Mukherjee A, Turashvili G, Green AR, McKinney S, Oloumi A, Shah S, Rosenfeld N, Murphy L, Bentley DR, Ellis IO, Purushotham A, Pinder SE, Børresen-Dale AL, Earl HM, Pharoah PD, Ross MT, Aparicio S and Caldas C: The somatic mutation profiles of 2,433 breast cancers refines their genomic and transcriptomic landscapes. Nat Commun 7: 11479, 2016. PMID: 27161491. DOI: 10.1038/ncomms 11479

46 Cerami E, Gao J, Dogrusoz U, Gross BE, Sumer SO, Aksoy BA, Jacobsen A, Byrne CJ, Heuer ML, Larsson E, Antipin Y, Reva B, Goldberg AP, Sander C and Schultz N: The cBio Cancer Genomics Portal: An open platform for exploring multidimensional cancer genomics data. Cancer Discov 2(5): 401-404, 2012. PMID: 22588877. DOI: 10.1158/2159-8290.CD-12-0095

47 Gao J, Aksoy BA, Dogrusoz U, Dresdner G, Gross B, Sumer SO, Sun Y, Jacobsen A, Sinha R, Larsson E, Cerami E, Sander C and Schultz N: Integrative analysis of complex cancer genomics and clinical profiles using the cBioPortal. Sci Signal 6(269): pl1, 2013. PMID: 23550210. DOI: 10.1126/scisignal.2004088

48 Chandrashekar DS, Bashel B, Balasubramanya SAH, Creighton CJ, Ponce-Rodriguez I, Chakravarthi BVSK and Varambally S: UALCAN: A portal for facilitating tumor subgroup gene expression and survival analyses. Neoplasia 19(8): 649-658, 2017. PMID: 28732212. DOI: 10.1016/j.neo.2017.05.002

49 Kao J, Salari K, Bocanegra M, Choi YL, Girard L, Gandhi J, Kwei KA, Hernandez-Boussard T, Wang P, Gazdar AF, Minna JD and Pollack JR: Molecular profiling of breast cancer cell lines defines relevant tumor models and provides a resource for cancer gene discovery. PLoS One 4(7): e6146, 2009. PMID: 19582160. DOI: 10.1371/journal.pone.0006146
50 Holliday DH and Speirs V: Choosing the right cell line for breast cancer research. Breast Cancer Res 13(4): 215, 2011. PMID: 21884641. DOI: $10.1186 /$ bcr2889

$51 \mathrm{Kim}$ DH, Behlke MA, Rose SD, Chang MS, Choi S and Rossi JJ: Synthetic dsRNA Dicer substrates enhance RNAi potency and efficacy. Nat Biotechnol 23(2): 222-226, 2005. PMID: 15619617. DOI: $10.1038 / \mathrm{nbt} 1051$

52 Nozaki Y, Motomura H, Tamori S, Kimura Y, Onaga C, Kanai S, Ishihara Y, Ozaki A, Hara Y, Harada Y, Mano Y, Sato T, Sato $\mathrm{K}$, Sasaki K, Ishiguro H, Ohno S and Akimoto K: High PKC $\lambda$ expression is required for ALDH1-positive cancer stem cell function and indicates a poor clinical outcome in late-stage breast cancer patients. PLoS One 15(7): e0235747, 2020. PMID: 32658903. DOI: 10.1371/journal.pone.0235747

53 Nozaki $Y$, Tamori S, Inada M, Katayama R, Nakane H, Minamishima O, Onodera Y, Abe M, Shiina S, Tamura K, Kodama D, Sato K, Hara Y, Abe R, Takasawa R, Yoshimori A, Shinomiya N, Tanuma S and Akimoto K: Correlation between cMet and ALDH1 contributes to the survival and tumor-sphere formation of ALDH1 positive breast cancer stem cells and predicts poor clinical outcome in breast cancer. Genes Cancer 8(7-8): 628639, 2017. PMID: 28966724. DOI: 10.18632/genesandcancer.148

54 Motomura H, Nozaki Y, Onaga C, Ozaki A, Tamori S, Shiina T,Kanai S, Ohira C, Hara Y, Harada Y, Takasawa R, Hanawa T, Tanuma S, Mano Y, Sato T, Sato K and Akimoto K: High expression of c-Met, PKC $\lambda$ and ALDH1A3 predicts a poor prognosis in late-stage breast cancer. Anticancer Res 40(1): 3552, 2020. PMID: 31892551. DOI: 10.21873/anticanres.13924

55 Fougner C, Bergholtz H, Norum JH and Sørlie T: Re-definition of claudin-low as a breast cancer phenotype. Nat Commun 11(1): 1787, 2020. PMID: 32286297. DOI: 10.1038/s41467-02015574-5

56 Kyndi M, Sørensen, FB, Knudsen H, Overgaard M, Nielsen HM and Overgaard J: Estrogen receptor, progesterone receptor, HER2 , and response to postmastectomy radiotherapy in high-risk breast cancer: The Danish Breast Cancer Cooperative Group. J Clin Oncol 26(9): 1419-1426, 2008. PMID: 18285604. DOI: 10.1200/JCO.2007.14.5565

57 Nguyen PL, Taghian AG, Katz MS, Niemierko A, Abi Raad RF, Boon WL, Bellon JR, Wong JS, Smith BL and Harris JR: Breast cancer subtype approximated by estrogen receptor progesterone receptor, and HER-2 is associated with local and distant recurrence after breast-conserving therapy. J Clin Oncol 26(14): 2373-2378, 2008. PMID: 18413639. DOI: 10.1200/JCO.2007.14.4287

58 Salaün C, Leroy C, Rousseau A, Boitez V, Beck L and Friedlander G: Identification of a novel transport-independent function of PiT1/SLC20A1 in the regulation of TNF-induced apoptosis. J Biol Chem 285(45): 34408-34418, 2010. PMID: 20817733. DOI: 10.1074/jbc.M110.130989

Received November 12, 2020

Revised November 26, 2020

Accepted November 27, 2020 